\section{BMJ Paediatrics Open}

\title{
Small head circumference at birth: an 8-year retrospective cohort study in China
}

Shiliang Liu, ${ }^{\oplus 1,2,3}$ Yanmei Pan, ${ }^{2}$ Nathalie Auger, ${ }^{\oplus}$ Wen Sun, ${ }^{2,3}$ Lijuan Dai, $^{2}$ Sihui Li, ${ }^{3}$ Sushan Xie, ${ }^{2}$ Shi Wu Wen, ${ }^{5}$ Dunjin Chen $^{2}$

To cite: Liu S, Pan Y, Auger N, et al. Small head circumference at birth: an 8-year retrospective cohort study in China. BMJ Paediatrics Open 2019;3:e000470. doi:10.1136/ bmjpo-2019-000470

- Additional material is published online only. To view please visit the journal online (http://dx.doi.org/10.1136/ bmjpo-2019-000470).

Received 25 February 2019 Revised 11 April 2019 Accepted 21 April 2019

\section{Check for updates}

(c) Author(s) (or their employer(s)) 2019. Re-use permitted under CC BY-NC. No commercial re-use. See rights and permissions. Published by BMJ.

${ }^{1}$ Maternal, Chid and Youth Heath Division, Centre for Surveillance and Applied Research, Public Health Agency of Canada, Ottawa, Ontario, Canada ${ }^{2}$ The Provincial Key Laboratory for Major Obstetric Disease, Third Affiliated Hospital, Guangzhou Medical University, Guangzhou, Guangdong, China ${ }^{3}$ School of Epidemiology and Public Health, Faculty of Medicine, University of Ottawa, Ottawa, Ontario, Canada ${ }^{4}$ University of Montreal Hospital Research Centre, Montreal, Quebec, Canada

${ }^{5}$ Ottawa Hospital Research Institute, Universityof Ottawa, Ottawa, Ontario, Canada

Correspondence to Dr Dunjin Chen; chendunjin@ hotmail.com

\section{ABSTRACT}

Objective Head circumference is considered a reliable assessment of the volume of the underlying brain. We sought to identify risk factors (maternal factors or antenatal antecedents) for microcephaly and to assess the effects of microcephaly on neonatal outcomes.

Design Retrospective cohort study.

Setting Data for all births in 2009-2017 were obtained from the Guangzhou Maternal-Fetal Care Database.

Participants All singleton liveborn infants between 33 and 42 weeks' gestation ( $n=45663$ ) were categorised using the Intergrowth-21st standard for microcephaly. Main outcome measures Prevalence of mild, absolute and relative microcephaly at birth. We estimated associations of (1) maternal characteristics including Cantonese origin, parity, exposure to teratogens, TORCH infections (ie, Toxoplasma gondii, rubella virus, cytomegalovirus, herpes simplex virus), in vitro fertilisation conception, pre-eclampsia and maternal congenital anomalies with risk of each category of microcephaly, and (2) microcephaly with risk of in-hospital mortality and severe morbidity.

Results A total of 2709 infants had a head circumference z-score $>2 \mathrm{SD}$, resulting in an overall prevalence of microcephaly of 59.3 per 1000 infants, consisting of mild (54.1 per 1000), absolute (2.8 per 1000) and relative microcephaly (2.4 per 1000). In multiple logistic regression, absolute microcephaly was associated with in utero exposure to teratogens $(\mathrm{OR} 4.2,95 \% \mathrm{Cl} 2.0$ to 8.8) and TORCH agents (OR 3.2, $95 \% \mathrm{Cl} 1.1$ to 9.5). Mild microcephaly was associated with Cantonese descent $(\mathrm{OR})$ $1.5,95 \% \mathrm{Cl} 1.3$ to 1.7$)$ and primiparity (OR $1.7,95 \% \mathrm{Cl}$ 1.5 to 2.0 ). Absolute microcephaly was associated with a significantly higher odds of neonatal seizure (OR 8.7, 95\% $\mathrm{Cl} 1.1$ to 69.1 ). Mild microcephaly was not associated with adverse neonatal outcomes overall.

Conclusions Cantonese origin, exposure to teratogens, pre-eclampsia and TORCH infection may be risk factors for microcephaly. The high prevalence of relative microcephaly and associated poor outcomes suggests that high-risk women merit closer clinical management and follow-up to maximise fetal head development during pregnancy.

\section{INTRODUCTION}

Microcephaly in the newborn is characterised by a disproportionately small head circumference (HC) for gestational age and may be categorised as absolute (asymmetrical growth
What is known about the subject?

Head circumference is considered a reliable assessment of the volume of the underlying brain.

- The recent outbreak of microcephaly associated with congenital Zika virus infection first identified in Brazil has drawn greater attention to Zika virus around the world.

\section{What this study adds?}

A high prevalence of microcephaly was identified in a predominantly Cantonese birth cohort in China with no documented evidence of Zika virus infection.

- In utero exposure to teratogens and TORCH (Toxoplasma gondii, rubella virus, cytomegalovirus, herpes simplex virus) agents were associated with a higher risk of absolute microcephaly.

- This study reinforces the applicability of a customised definition of absolute and relative microcephaly.

retardation-where the $\mathrm{HC}$ is reduced to a greater extent than length and weight) or relative (symmetrical growth retardation-where the $\mathrm{HC}$, the length and weight are reduced to a similar degree). ${ }^{12}$ Despite considerable advances in case ascertainment, microcephaly remains a heterogeneous group of primarily neurological deficits. ${ }^{2-6}$ HC is considered a reliable assessment of the volume of the underlying brain. WHO currently recommends the Intergrowth-21st criteria to classify $\mathrm{HC}$ if the gestational age is known. ${ }^{7-9}$ However, there exist a number of methods for microcephaly ascertainment, including $>2 \mathrm{SD}$ or $>3 \mathrm{SD}$ below mean HC. In addition, ethnicity is another factor to consider, as norms for HC may depend on the population for whom the standard was created. As such, prevalence rates of microcephaly vary greatly by country, ethnicity and region or even birth hospital where the standards and case ascertainment methods are used. ${ }^{10-14}$ 
Unlike intrauterine growth restriction (IUGR) or small for gestational age, the underlying cause/aetiology for microcephaly is reported to be largely genetic or unknown. ${ }^{24-6}$ Devakumar et al recently summarised several major maternal infections such as cytomegalovirus, herpes simplex virus (HSV), rubella virus, Toxoplasma gondii and Zika virus as known causes for congenital microcephaly. ${ }^{15}$ In high-income countries, however, microcephaly was reportedly due to non-infectious causes. ${ }^{10}{ }^{13} 16-19$ A recent study of hospital birth data from Quebec, Canada, reported that the strongest non-genetic risk factor for microcephaly was TORCH (ie, $T$. gondii, rubella virus, cytomegalovirus, HSV) infection with a 32-fold risk, and in utero exposure to teratogens (ie, alcohol or drug use) with an over threefold risk of microcephaly despite an observed low prevalence. ${ }^{13}$ The recent outbreak of microcephaly associated with congenital Zika virus infection, first identified in Brazil, has drawn attention to Zika virus because the outbreak led to congenital microcephaly in a susceptible population, affecting a very large number of infants. ${ }^{20-22}$

The Intergrowth-21st Project recently published HC standards based on a low-risk population of fetuses and newborn infants. ${ }^{7}$ According to the standard, $9.8 \%$ of singleton live births from 2009 to 2012 in Guangzhou are below the third centile of $\mathrm{HC}$, and $12.1 \%$ are in the third to the 10th centile. ${ }^{23}$ This surprisingly high rate of small HC calls for close assessment of this population. In this retrospective cohort study, we aimed to characterise microcephalic infants, to identify risk factors (maternal factors or antenatal antecedents) for microcephaly and to assess the effects of microcephaly on neonatal outcomes.

\section{METHODS}

\section{Guangzhou Maternal-Fetal Care Database}

This database was created following the Canadian perinatal health surveillance and research data source guidelines ${ }^{24}$ and contains all records of hospital deliveries $(\geq 22$ weeks of gestation) at Metropolitan Guangzhou Tertiary Care Centre for Pregnant Women. The hospitalisation records are collated by trained medical record personnel using standardised definitions ${ }^{24}$ and contain information on gestational age (ultrasound-based estimate), plurality, birth weight, laboratory tests, ultrasounds, maternal and newborn conditions (principal diagnosis and up to 24 secondary diagnostic fields) during antenatal hospital visits and the obstetric delivery/neonatal admission. Data collection began in 2008, and the data are routinely checked for accuracy and completeness. ${ }^{25}$ Information on maternal demographic characteristics (eg, ethnicity, birth place, education, occupation, current residence, age, parity), conception method (natural, in vitro fertilisation (IVF)), prenatal care or medical visits, laboratory tests, neonatal conditions including Apgar scores, length of hospital stay and discharge status is recorded in the database. ${ }^{23-25}$ Medical conditions, diagnoses, and diagnostic, therapeutic and surgical procedures among mothers and newborns were coded using the International Statistical Classification of Diseases and Related Health Problems, 10th Revision (ICD-10, WHO). Newborn birth weight (gram), femur length (centimetre), HC (centimetre) are all measured and recorded at birth. In addition, all delivering mothers and newborns (including stillbirths) are linked using mother-newborn dyad numbers assigned at birth. Stillbirths and live births with central nervous system anomalies were excluded from this study population to minimise potential confounding of the assessment of small HC.

\section{Identification of microcephaly}

We analysed three primary outcomes, including absolute, relative and mild microcephaly (figure 1 ). To categorise the outcomes, we first identified all singleton infants between 33 and 42 weeks' gestation who satisfied the Intergrowth-21st standard for microcephaly. We used the Intergrowth criteria to define microcephaly as an $\mathrm{HC}$ z-score $>2$ SD below the mean, ${ }^{78}$ and further characterised infants who satisfied the criteria into four subtypes: (1) absolute microcephaly defined as an $\mathrm{HC}>3 \mathrm{SD}$ below the mean with 'normal' (ie, $\geq 3$ rd centile) birth weight; (2) relative microcephaly defined as an $\mathrm{HC}>3$ SD below the mean with 'low' (ie, <3rd centile) birth weight and (3) mild microcephaly infants whose HC was between 2 and 3 SD below the mean with 'normal' birth weight; (4) infants with both $\mathrm{HC} \leq 2 \mathrm{SD}$ below the mean and normal birth weight were defined as normocephaly and used as the comparison group (figure 1).

Absolute and relative microcephaly both captured $\mathrm{HC}>3$ SD below the mean, but distinguished infants on body size or birth weight. Absolute microcephaly included infants whose birth weight was $\geq 3$ rd centile of the distribution. In contrast, relative microcephaly included infants whose birth weight was $\leq 3$ rd centile of the distribution. Relative microcephaly is generally more severe than absolute microcephaly and may be a marker of growth restriction overall. The category mild microcephaly was a variant of absolute microcephaly, capturing infants categorised as microcephalic by Intergrowth-21st standards, but with an $\mathrm{HC}>2 \mathrm{SD}$ of the mean and birth weight $\geq 3$ rd centile. Our hypothesis was that risk factors, birth outcomes and neonatal morbidity and mortality for absolute, relative and mild microcephaly may vary.

\section{Maternal factors and antenatal antecedents}

We characterised maternal demographics and risk factors for the three types of microcephaly. We considered maternal age at conception $(<25,25-29,30-34$ and $\geq 35$ years), mother's ethnicity (Cantonese women vs women migrated from other provinces of China), parity (first vs $\geq$ second child), conception method (IVF vs natural), pregnancy condition (ie, pre-existing hypertension, gestational hypertension, pre-eclampsia/eclampsia, gestational and pregestational diabetes mellitus), ${ }^{17} 18$ exposure to teratogens (ie, maternal use of substances or behavioural risk factors) including prenatal and/or 


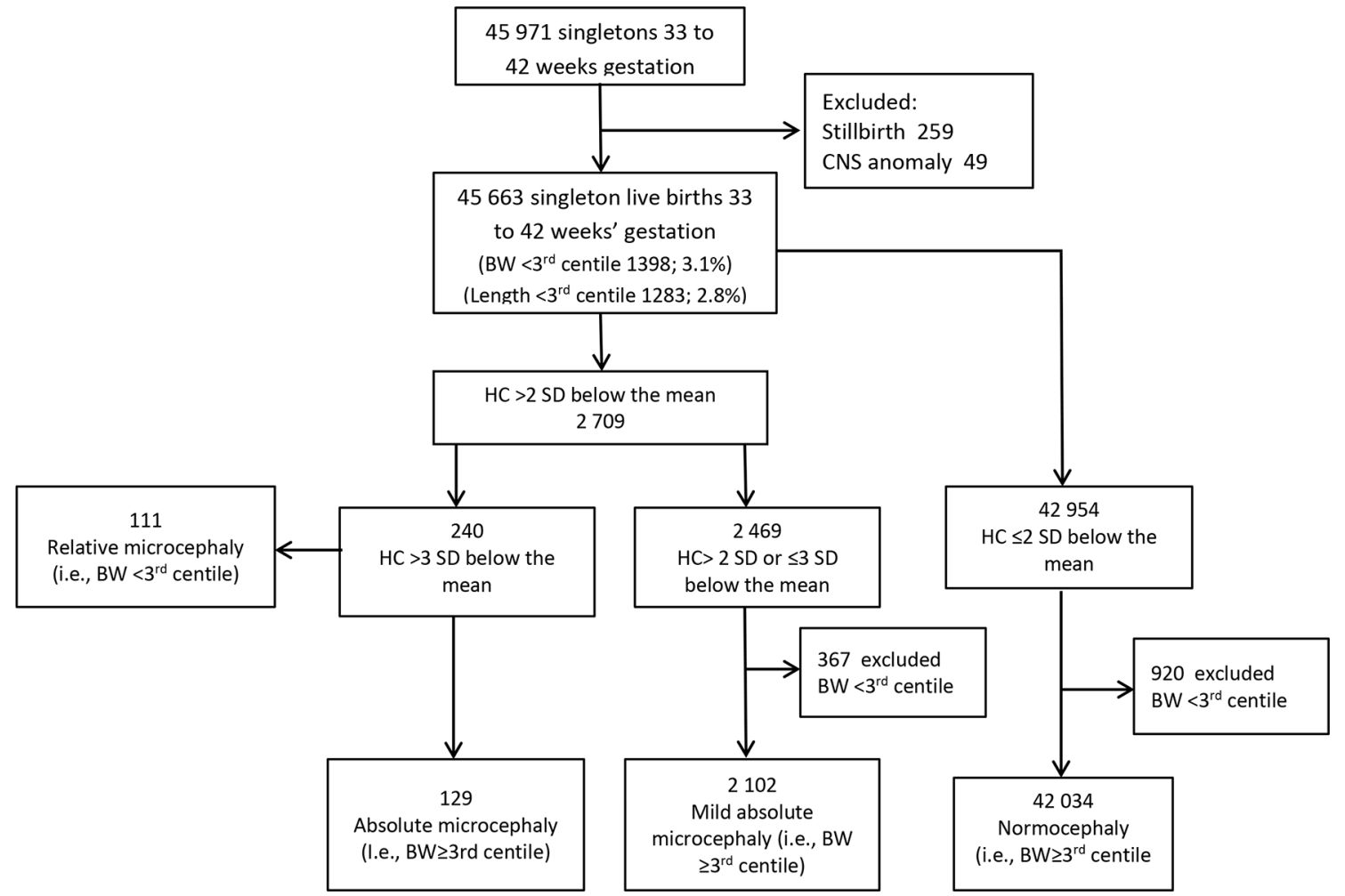

Figure 1 Flow chart detailing identification of microcephaly in Guangzhou tertiary care centre for pregnant women. BW, birth weight; CNS, central nervous system; HC, head circumference.

perinatal use of alcohol, cigarette or medicinal or other illicit or therapeutic drugs ${ }^{1326} 27$ and TORCH infections during pregnancy. In addition, we included congenital heart defects and other anomalies as the former has been strongly associated with microcephaly. ${ }^{3513}$ We used ICD-10 codes to document whether women had these conditions during pregnancy and/or at the time of delivery (online supplementary appendix table 1). In addition, we defined three maternal educational levels as university or college ( $>12$ years of school), high school (10-12 years) and elementary school ( $<10$ years). We used educational attainment as a proxy for socioeconomic status (SES) and family wealth.

We assessed infant status or poor birth outcomes (preterm birth, $1 \mathrm{~min}$ and 5 min Apgar scores) and respiratory distress syndrome and comorbidities (necrotising enterocolitis, intracranial haemorrhage, bronchopulmonary dysplasia, birth hypoxia, seizure, feeding difficulties). We also assessed mean length of stay after delivery, including $>7$ or $>10$ days of hospital stay. We determined neonatal in-hospital mortality according to discharge summaries (online supplementary appendix table 1).

\section{Statistical analysis}

We calculated prevalence rates of absolute, relative and mild microcephaly per 1000 live births. We used simple logistic regression to estimate crude ORs, and multiple logistic regression to estimate adjusted ORs (AORs) and 95\% CIs for the association between maternal risk factors and absolute, relative or mild microcephaly. Finally, we assessed associations between microcephaly as the fetal exposure and poor birth outcomes or comorbidities in models adjusted for infant gender, parity, maternal age, ethnicity, education, TORCH agents, exposure to teratogens, pre-eclampsia, diabetes mellitus and chronic illness. All variables were entered simultaneously in multiple logistic regression models. A modelling selection process was not applied. In addition, we tested for multicollinearity among independent variables. ${ }^{28}$ Statistical analyses were undertaken with SAS version 9.4 (SAS Institute, Cary, North Carolina) software.

\section{Patient and public involvement}

As this study was based on predesigned and ongoing collection of birth hospitalisation data for newborns and the mothers, no patients were involved in setting the research question or outcome measures, nor were they involved in developing plans for implementation of the study. No patients were asked to comment on the study design or were consulted to interpret the results. Patients were not invited to contribute to writing or editing this document for readability or accuracy.

\section{RESULTS}

Among 45663 singleton live births of 33 to 42 weeks' gestation, $3.1 \%(\mathrm{n}=1398)$ had birth weight $<3$ rd centile and $2.8 \%(n=1283)$ had femur length $<3$ rd centile. The majority $(85.2 \%)$ of mothers were of Cantonese origin and $81.2 \%$ were primiparous.

A total of 2709 liveborns had $\mathrm{HC}>2$ SD below the mean, resulting in an overall prevalence of microcephaly 
Table 1 Maternal characteristics and factors and risk of absolute microcephaly in the offspring

\begin{tabular}{|c|c|c|c|c|c|}
\hline \multirow[b]{2}{*}{ Characteristic } & \multirow{2}{*}{$\begin{array}{l}\text { Absolute } \\
\text { microcephaly }\end{array}$} & \multirow{2}{*}{$\begin{array}{l}\text { Non- } \\
\text { microcephaly }\end{array}$} & \multirow{2}{*}{$\begin{array}{l}\text { Prevalence } \\
\text { per } 1000\end{array}$} & \multicolumn{2}{|l|}{$\begin{array}{l}\text { OR } \\
95 \% \mathrm{Cl}\end{array}$} \\
\hline & & & & Unadjusted & Adjusted* \\
\hline \multicolumn{6}{|l|}{ Maternal age (years) } \\
\hline$<25$ & 31 & 5244 & 5.9 & 2.14 (1.33 to 3.44$)$ & 1.51 (0.90 to 2.53$)$ \\
\hline $25-29$ & 51 & 18263 & 2.8 & 1.01 (0.66 to 1.54$)$ & $0.92(0.59$ to 1.41$)$ \\
\hline $30-34$ & 38 & 13730 & 2.8 & 1.00 (reference) & 1.00 (reference) \\
\hline$\geq 35$ & 9 & 6899 & 1.3 & 0.47 (0.23 to 0.98$)$ & 0.47 (0.23 to 0.99$)$ \\
\hline \multicolumn{6}{|l|}{ Education } \\
\hline University/college & 61 & 26775 & 2.3 & 1.00 (reference) & 1.00 (reference) \\
\hline High school & 22 & 6576 & 3.3 & 1.47 (0.90 to 2.39$)$ & $1.27(0.72$ to 2.11$)$ \\
\hline Elementary school & 46 & 10785 & 4.2 & 1.87 (1.28 to 2.75$)$ & 1.57 (1.02 to 2.40$)$ \\
\hline Primiparity & 105 & 35902 & 2.9 & 1.00 (0.64 to 1.56$)$ & 1.42 (0.87 to 2.32$)$ \\
\hline Cantonese ethnicity & 110 & 37591 & 2.9 & 1.01 (0.62 to 1.64$)$ & 0.95 (0.57 to 1.56$)$ \\
\hline IVF conception & 7 & 2576 & 2.9 & 0.93 (0.43 to 1.99$)$ & 1.12 (0.51 to 2.46$)$ \\
\hline Congenital heart disease & 6 & 445 & 13.5 & 4.79 (2.10 to 10.93$)$ & 2.33 (0.97 to 5.63$)$ \\
\hline $\begin{array}{l}\text { Other congenital anomalies in } \\
\text { offspring } \dagger\end{array}$ & 3 & 440 & 6.8 & 2.37 (0.75 to 7.46$)$ & 1.33 (0.38 to 4.67$)$ \\
\hline Intrauterine growth restriction & 6 & 212 & 27.5 & 10.1 (4.41 to 23.2 ) & 4.92 (2.04 to 11.9$)$ \\
\hline Maternal anomalies & 3 & 390 & 7.6 & 2.67 (0.85 to 8.43$)$ & 2.34 (0.73 to 7.53$)$ \\
\hline Diabetes mellitus & 10 & 5311 & 1.9 & 0.61 (0.32 to 1.17$)$ & 0.75 (0.39 to 1.44$)$ \\
\hline Pre-eclampsia & 8 & 863 & 9.2 & 3.32 (1.62 to 6.80$)$ & 2.64 (1.25 to 5.59$)$ \\
\hline Chronic illness & 24 & 6303 & 3.8 & 1.37 (0.88 to 2.14$)$ & $1.43(0.91$ to 2.24$)$ \\
\hline Teratogens & 8 & 626 & 12.6 & 4.60 (2.24 to 9.44$)$ & 4.18 (1.98 to 8.77$)$ \\
\hline TORCH agentsł & 4 & 324 & 12.2 & 4.33 (1.59 to 11.8$)$ & 3.21 (1.09 to 9.49$)$ \\
\hline Genital/reproductive infections & 1 & 688 & 1.5 & 0.49 (0.07 to 3.53$)$ & $0.57(0.07$ to 4.16$)$ \\
\hline Overall & 129 & 44136 & 2.9 & & \\
\hline
\end{tabular}

${ }^{*}$ Adjusted for infant birth year.

†Exclusive of congenital heart disease and CNS anomalies.

łLatent Toxoplasma gondii only.

CNS, central nervous system; IVF, in vitro fertilisation; TORCH, Toxoplasma gondii, rubella virus, cytomegalovirus, herpes simplex virus.

of 59.3 per 1000 infants. After excluding the $<3$ rd centile for birth weight, there remained 2102 infants $(46.0$ per 1000 ) with mild 'absolute' microcephaly. A total of 240 'severe' microcephaly infants were identified, yielding an overall prevalence of 5.2 per 1000 live births. There were 129 infants with absolute microcephaly (2.8 per 1000$)$ and 111 infants with relative microcephaly (2.4 per 1000$)$ (figure 1).

Absolute microcephaly was associated with maternal exposure to teratogens (AOR 4.2, 95\% CI 2.0 to 8.8 ) and TORCH agents (AOR 3.2, 95\% CI 1.1 to 9.5). In addition, IUGR and pre-eclampsia were, respectively, associated with a nearly fivefold and threefold increased risk of absolute microcephaly (table 1). Relative microcephaly was significantly associated with IUGR (AOR 20.2, 95\% CI 12.2 to 33.5), pre-eclampsia/eclampsia (AOR 5.3, 95\% CI 3.1 to 8.9 ), TORCH agents (AOR 3.0, 95\% CI 1.1 to 7.9$)$ and elementary school or lower education (AOR 2.6, 95\% CI 1.6 to 4.1). Relative microcephaly was significantly associated with congenital heart defects (AOR 3.4, 95\% CI 1.6 to 7.1) (table 2).

In multiple logistic regression, mothers' Cantonese origin (AOR 1.45, 95\% CI 1.25 to 1.68), primiparity (AOR 1.7, 95\% CI 1.5 to 2.0 ) and young maternal age were associated with a higher risk of mild microcephaly. Maternal age $<25$ years was associated with $30 \%$ higher risk of mild microcephaly (AOR $1.3,95 \%$ CI 1.1 to 1.4 ) versus 30-34 years. IVF conception was associated with a $22 \%$ decreased risk of mild microcephaly (table 3 ). Multicollinearity tests did not show meaningful evidence of collinearity between exposure variables.

Compared with normocephaly, absolute microcephaly was associated with a significantly higher odds of neonatal seizure (AOR 8.7, 95\% CI 1.1 to 69.1), preterm birth (AOR 2.0, 95\% CI 1.2 to 3.2), 1 min Apgar scores $<8$ (AOR 2.0, $95 \%$ CI 1.1 to 4.1 ) and longer in-hospital stay (AOR $3.2,95 \%$ CI 1.9 to 5.4 ). In contrast, relative microcephaly was associated with poor birth outcomes and neonatal 
Table 2 Maternal characteristics and factors and risk of relative microcephaly in the offspring

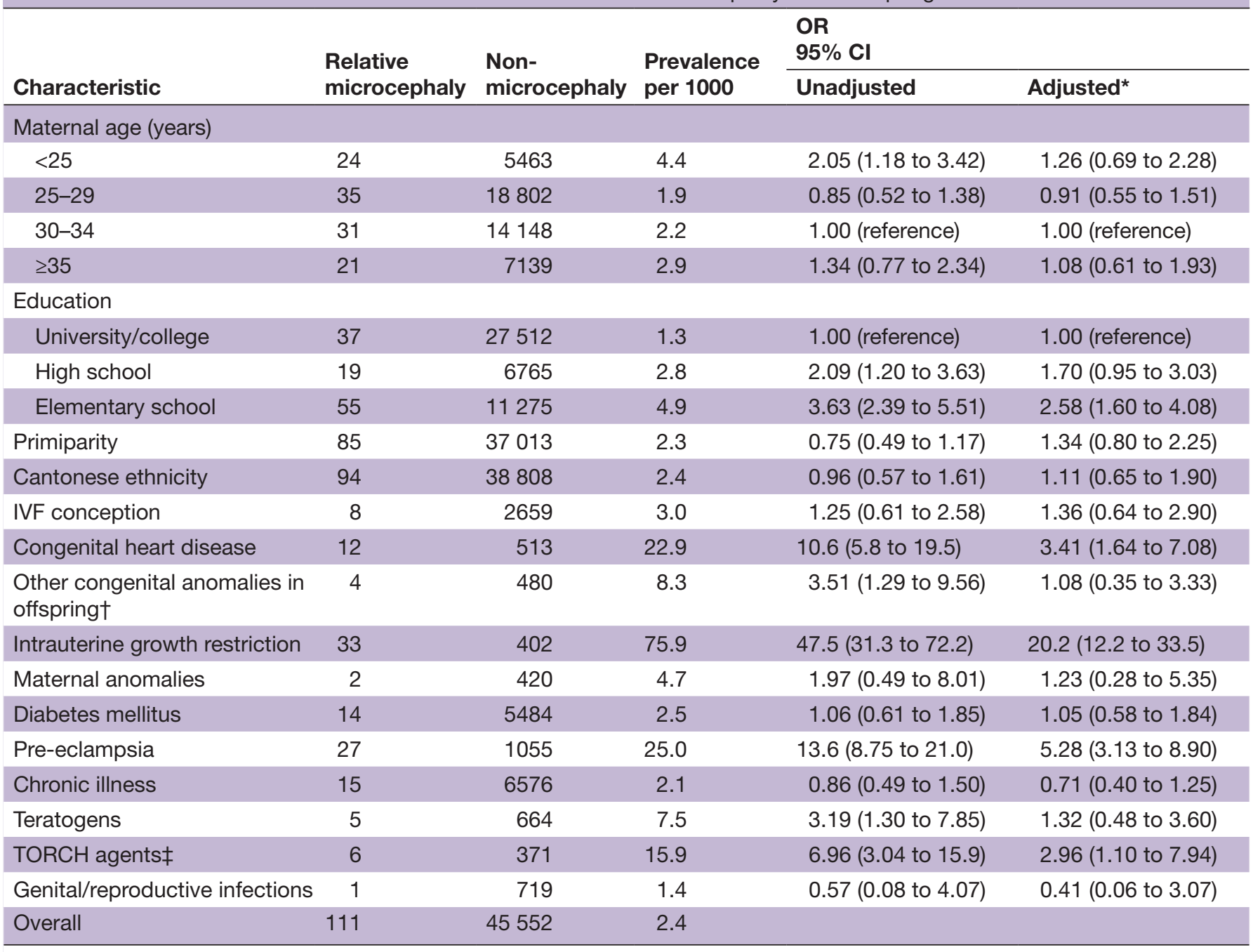

${ }^{*}$ Adjusted for infant birth year.

†Exclusive of congenital heart disease and CNS anomalies.

łLatent Toxoplasma gondii only.

CNS, central nervous system; IVF, in vitro fertilisation; TORCH, Toxoplasma gondii, rubella virus, cytomegalovirus, herpes simplex virus.

morbidity, including significantly higher preterm birth (AOR 1.7, 95\% CI 1.0 to 2.7), 1 min Apgar scores $<8$ (AOR 2.6, 95\% CI 1.4 to 4.9), 5 min Apgar scores $<8$ (AOR 3.6, $95 \%$ CI 1.2 to 10.7), intracranial haemorrhage (AOR 7.0, 95\% CI 2.4 to 20.1), bronchopulmonary dysplasia (AOR $10.1,95 \%$ CI 1.2 to 82.2 ), birth hypoxia (AOR 2.6, $95 \%$ CI 1.3 to 5.3), longer in-hospital stay (AOR 4.7, 95\% CI 3.0 to 7.5) and higher neonatal in-hospital mortality (AOR $11.7,95 \%$ CI 4.3 to 31.7 ) compared with normocephaly (table 4). However, infants with mild microcephaly had good birth outcomes overall with comparable neonatal comorbidity and length of in-hospital stay relative to normocephaly. It is noteworthy that mild microcephaly was associated with lower odds of preterm birth (table 5).

\section{DISCUSSION}

We found an unexpectedly high rate of small $\mathrm{HC}$, including absolute, relative and mild microcephaly, in a predominately
Cantonese liveborn cohort in southern China. We analysed several markers capturing the severity and degree of microcephaly. Primiparity, pre-eclampsia, younger maternal age, TORCH agents and lower education attainment were all associated with an increased risk of smaller $\mathrm{HC}$, with variations across absolute, relative and mild microcephaly. Some of the associations may be explained by a large number of infants born to Cantonese mothers (eg,table 3), whose statute is smaller than women in other parts of China, ${ }^{29}$ although the underlying relationship is complex. In addition to well-established IUGR, ${ }^{24}$ factors such as genetics/ ethnicity, nutrients (ie, excess seafood) and heavy air pollution in metro Guangzhou may relate to the increased small HC. ${ }^{16} 1730$ Moreover, our results suggest that absolute and relative microcephaly are distinct, with relative microcephaly associated with a wide range of adverse neonatal outcomes given the significant effect of IUGR, and absolute microcephaly associated with adverse neurological outcomes but 
Table 3 Maternal characteristics and factors associated with risk of mild microcephaly

\begin{tabular}{|c|c|c|c|c|c|}
\hline \multirow[b]{2}{*}{ Characteristic } & \multirow{2}{*}{$\begin{array}{l}\text { Mild } \\
\text { microcephaly }\end{array}$} & \multirow[b]{2}{*}{ Normocephaly } & \multirow{2}{*}{$\begin{array}{l}\text { Prevalence } \\
\text { rate per } 100\end{array}$} & \multicolumn{2}{|l|}{$\begin{array}{l}\text { OR } \\
95 \% \mathrm{Cl}\end{array}$} \\
\hline & & & & Unadjusted & Adjusted* $^{\star}$ \\
\hline \multicolumn{6}{|l|}{ Maternal age (years) } \\
\hline$<25$ & 312 & 4932 & 6.0 & 1.37 (1.19 to 1.58$)$ & 1.29 (1.06 to 1.42$)$ \\
\hline 25-29 & 988 & 17275 & 5.4 & 1.24 (1.12 to 1.38$)$ & 1.13 (1.01 to 1.25$)$ \\
\hline $30-34$ & 605 & 13125 & 4.4 & 1.00 (reference) & 1.00 (reference) \\
\hline$\geq 35$ & 197 & 6702 & 2.9 & 0.64 (0.54 to 0.75$)$ & 0.54 (0.41 to 0.72$)$ \\
\hline \multicolumn{6}{|l|}{ Education } \\
\hline University/college & 1311 & 25464 & 4.9 & 1.00 (reference) & 1.00 (reference) \\
\hline High school & 312 & 664 & 4.7 & 0.97 (0.85 to 1.10$)$ & 0.99 (0.87 to 1.13$)$ \\
\hline Elementary school & 479 & 10306 & 4.6 & $0.90(0.81$ to 1.01$)$ & 1.02 (0.91 to 1.14$)$ \\
\hline Primiparity & 1850 & 34052 & 5.2 & 1.72 (1.51 to 1.97$)$ & 1.73 (1.50 to 2.01$)$ \\
\hline Cantonese ethnicity & 1888 & 35703 & 5.0 & $1.56(1.36$ to 1.81$)$ & 1.45 (1.25 to 1.68$)$ \\
\hline IVF conception & 89 & 2487 & 3.5 & 0.72 (0.57 to 0.89$)$ & 0.78 (0.65 to 0.96$)$ \\
\hline Congenital heart disease & 22 & 423 & 4.9 & 1.04 (0.68 to 1.60$)$ & 0.89 (0.57 to 1.38$)$ \\
\hline $\begin{array}{l}\text { Other congenital anomalies in } \\
\text { offspringt }\end{array}$ & 25 & 415 & 5.7 & $1.21(0.80$ to 1.81$)$ & $1.23(0.81$ to 1.86$)$ \\
\hline Intrauterine growth restriction & 40 & 172 & 18.8 & 4.72 (2.34 to 6.68$)$ & 4.48 (3.14 to 6.40$)$ \\
\hline Maternal anomalies & 15 & 375 & 3.9 & $0.80(0.48$ to 1.34$)$ & 0.80 (0.48 to 1.35$)$ \\
\hline Diabetes mellitus & 216 & 5095 & 4.1 & 0.83 (0.72 to 0.96$)$ & 0.96 (0.83 to 1.11$)$ \\
\hline Pre-eclampsia & 44 & 819 & 5.1 & $1.08(0.79$ to 1.46$)$ & $1.10(0.81$ to 1.51$)$ \\
\hline Chronic illness & 276 & 6027 & 4.4 & 0.90 (0.79 to 1.03$)$ & $0.92(0.81$ to 1.05$)$ \\
\hline Teratogens & 35 & 591 & 5.6 & $1.18(0.84$ to 1.67$)$ & $1.22(0.86$ to 1.73$)$ \\
\hline TORCH agents $\ddagger$ & 11 & 313 & 3.4 & 0.70 (0.38 to 1.28$)$ & 0.70 (0.38 to 1.28$)$ \\
\hline Genital/reproductive infections & 19 & 669 & 2.8 & 0.56 (0.36 to 0.89$)$ & 0.66 (0.42 to 1.06$)$ \\
\hline Overall & 2102 & 42034 & 4.8 & & \\
\hline
\end{tabular}

${ }^{*}$ Adjusted for infant birth year.

†Exclusive of congenital heart disease and CNS anomalies.

łLatent Toxoplasma gondii only.

CNS, central nervous system; IVF, in vitro fertilisation; TORCH, Toxoplasma gondii, rubella virus, cytomegalovirus, herpes simplex virus.

fewer comorbidities overall. Mild microcephaly differed little from normocephaly with respect to comorbidities, in-hospital mortality and hospital length of stay. In this study, we were initially concerned by absolute microcephaly as these children are more likely to have future intellectual disability. ${ }^{1-431}$

Microcephaly is a clinical sign, not a diagnosis. ${ }^{245}$ Microcephaly is usually defined as an occipitofrontal HC of 2 or 3 SD below the mean on age-matched and sex-matched curves. $^{2532}$ Primary or congenital microcephaly is usually identified during neonatal examinations before birth hospital discharge, but may also be detected with measurements of $\mathrm{HC}$ in utero during ultrasound screening. ${ }^{33}$ According to US surveillance data, the prevalence of congenital microcephaly varies from 2 to 12 cases per 10 000 infants. $^{11}$ In one study, the prevalence of microcephaly was 8.7 per 10000 live births based on 30 birth defect surveillance programme covering 11 million live births in the USA. ${ }^{16}$ In Europe, the overall prevalence is approximately
2.6 to 2.9 per 10000 live births; however, rates vary greatly between countries. ${ }^{10}$ A recent study from Quebec, Canada, reported an overall microcephaly prevalence of 4.1 per 10 000 live births between 1989 and 2012, fluctuating between 3.0 and 5.3 per 10000 annually. ${ }^{13}$ However, these prevalence rates are from routine birth surveillance data and may be underestimated, as measurement of microcephaly is not based on standardised diagnostic criteria. ${ }^{1-5}$ Different operational definitions of microcephaly make it difficult to evaluate rates across studies. Moreover, HC measurements could be more representative of congenital microcephaly recognised clinically ${ }^{6}$ and have the advantage of allowing researchers to distinguish cases as relative, absolute or mild.

Our results suggested that IVF was associated with an increased HC compared with natural conception. Previous studies report conflicting findings on fetal growth and HC following assisted reproductive techniques. ${ }^{34-36}$ Further study including characteristics such as origin/ethnicity of sperm/egg donors may be helpful 


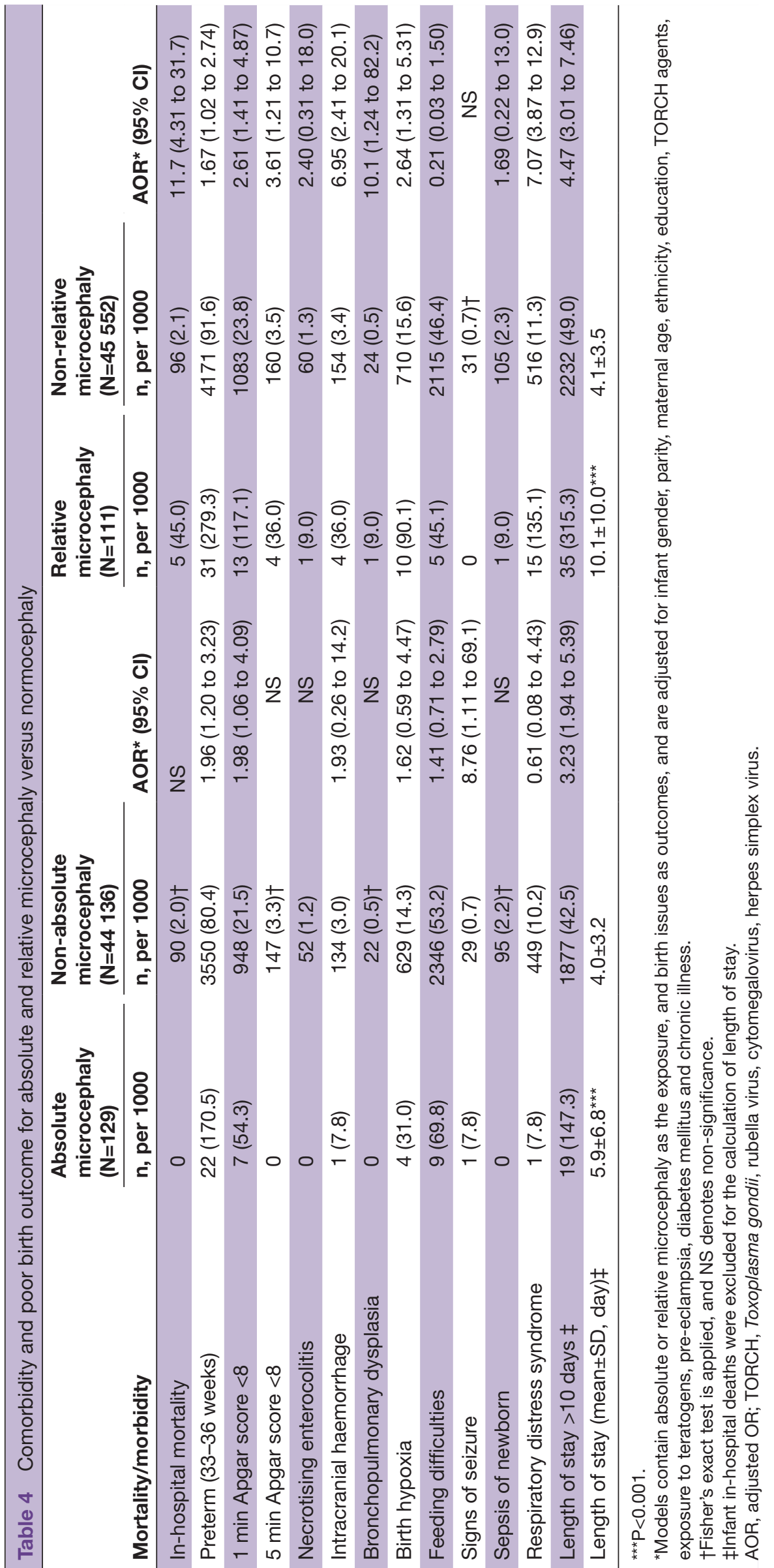


Table 5 Comorbidity and poor birth outcome for mild microcephaly versus normocephaly

\begin{tabular}{|c|c|c|c|c|c|c|}
\hline \multirow[b]{2}{*}{ Mortality/morbidity } & \multicolumn{2}{|c|}{$\begin{array}{l}\text { Mild microcephaly } \\
(n=2102)\end{array}$} & \multicolumn{2}{|c|}{$\begin{array}{l}\text { Normocephaly } \\
(n=42034)\end{array}$} & \multicolumn{2}{|l|}{ OR } \\
\hline & Infants (n) & $\begin{array}{l}\text { Prevalence } \\
\text { per } 1000\end{array}$ & Infants (n) & $\begin{array}{l}\text { Prevalence } \\
\text { per } 1000\end{array}$ & $\begin{array}{l}\text { Unadjusted OR } \\
(95 \% \mathrm{Cl})\end{array}$ & $\begin{array}{l}\text { Adjusted OR* } \\
(95 \% \mathrm{Cl})\end{array}$ \\
\hline In-hospital mortality & 5 & 2.0 & 85 & 2.0 & 1.18 (0.48 to 2.90$)$ & 1.21 (0.49 to 3.00$)$ \\
\hline Preterm (33-36 weeks) & 80 & 38.4 & 3470 & 82.6 & 0.45 (0.36 to 0.55$)$ & $0.45(0.35$ to 0.56$)$ \\
\hline 1 min Apgar score $<8$ & 45 & 21.4 & 939 & 22.3 & $0.96(0.71$ to 1.30$)$ & 0.98 (0.72 to 1.33$)$ \\
\hline 5 min Apgar score $<8$ & 6 & 2.9 & 141 & 3.4 & 0.85 (0.38 to 1.93$)$ & $0.83(0.37$ to 1.90$)$ \\
\hline Necrotising enterocolitis & 3 & 1.6 & 49 & 1.2 & 1.23 (0.38 to 3.93$)$ & 1.26 (0.39 to 4.05$)$ \\
\hline Intracranial haemorrhage & 9 & 3.2 & 125 & 3.0 & $1.44(0.73$ to 2.84$)$ & $1.58(0.80$ to 3.15$)$ \\
\hline Bronchopulmonary dysplasia & 1 & 0.4 & 21 & 0.5 & 0.95 (0.13 to 7.08$)$ & $1.03(0.14$ to 8.04$)$ \\
\hline Birth hypoxia & 35 & 16.2 & 594 & 14.1 & $1.18(0.84$ to 1.67$)$ & $1.21(0.85$ to 1.71$)$ \\
\hline Feeding difficulties & 103 & 55.0 & 2243 & 53.4 & 0.91 (0.75 to 1.12$)$ & $0.89(0.72$ to 1.09$)$ \\
\hline Signs of seizure & 1 & 0.5 & 27 & 0.7 & $0.74(0.33$ to 5.63$)$ & $0.76(0.34$ to 5.66$)$ \\
\hline Sepsis of newborn & 5 & 2.4 & 90 & 2.1 & $1.11(0.45$ to 2.74$)$ & 1.09 (0.44 to 2.68$)$ \\
\hline Respiratory distress syndrome & 14 & 6.3 & 435 & 10.3 & 0.64 (0.38 to 1.09$)$ & $0.71(0.42$ to 1.22$)$ \\
\hline Length of stay $>7$ days $\dagger$ & 197 & 93.7 & 3916 & 93.2 & $1.01(0.87$ to 1.17$)$ & 1.07 (0.91 to 1.39$)$ \\
\hline Length of stay (mean $\pm S D$, day) & $3.84 \pm 3.66$ & & $3.97 \pm 3.21$ & & $P=0.11$ & \\
\hline
\end{tabular}

*Models contain mild microcephaly (vs normocephaly) as the exposure, and birth issues as outcomes, and are adjusted for infant gender, parity, maternal age, ethnicity, education, TORCH agents, exposure to teratogens, pre-eclampsia, diabetes mellitus and chronic illness.

†Infant in-hospital deaths were excluded for the calculation of length of stay.

TORCH, Toxoplasma gondii, rubella virus, cytomegalovirus, herpes simplex virus.

for clarification. The association of in utero exposure to teratogens with absolute microcephaly was, however, consistent with previous studies. ${ }^{13} 1819263738$ Exposures to teratogens or substances such as cocaine, opioids and alcohol are known risk factors for microcephaly ${ }^{46} 3738$ and other neurological developmental abnormalities. ${ }^{27}$ Another recent study from Quebec, Canada, found that neonatal abstinence syndrome (a proxy for exposure to maternal opioids exposure) was associated with a 16-fold higher risk (adjusted risk ratio 16.4, 95\% CI 9.4 to 28.6) of congenital microcephaly. ${ }^{26}$

Maternal exposure to TORCH agents and pre-eclampsia appeared to increase the risk of relative microcephaly (table 2). Previous studies have already linked severe fetal growth restriction to pre-eclampsia and TORCH agents including T. gondii. ${ }^{15} 171839$ According to ICD codes, we most likely captured maternal latent TORCH infections, in particular, for T. gondii. ${ }^{39} 40$ Other TORCH agents were not included in our data despite evidence that outbreaks of chikungunya and dengue occurred in the study areas. ${ }^{41} 42$ T. gondii infection during pregnancy has also been found to play a role in absolute microcephaly, aligning with our study results.

We observed significantly increased risks of neonatal seizure, preterm birth and poor 1 min Apgar scores for absolute microcephaly, reflecting a possible higher risk of neurological developmental abnormality and adverse intellectual prognosis. ${ }^{12530}$ Our findings reflect great variations among absolute, relative and mild microcephalic infants despite no follow-up data on their future neurological development.
There are several limitations inherent to our study. First, there currently is no standardised definition or classification for microcephaly. Hospital discharge data may underestimate the prevalence, as many cases may not be reported despite meeting the clinical definition of microcephaly. Second, selection bias could have occurred if women with high-risk pregnancies were more likely to deliver at a tertiary care centre. Our analysis is based on a single large tertiary hospital in Guangzhou metromunicipal region rather than a population-based setting. We had consistent measurements of $\mathrm{HC}$ at birth, but follow-up information on head growth after discharge from hospital was not available. Although there may be issues with generalisability, our study adds to the portrait of microcephaly in China, using a multiyear cohort of hospital live births with no documented evidence of Zika. In addition, we could not adjust for indicators of SES apart from education.

In conclusion, we found a high prevalence of absolute, relative and mild microcephaly in a predominantly Cantonese birth cohort in China. Several risk factors including in utero exposure to teratogens, IUGR and TORCH agent played a role in the elevated rate of microcephaly. Relative and absolute microcephaly were associated with diverse risk factor profiles and neonatal outcomes, but these factors were not related to mild microcephaly. Our findings suggest that in addition to pre-eclampsia, in utero exposure to teratogens and infectious agents were the largest contributors to absolute microcephaly. Preventable risk factors such as teratogens and TORCH agents highlight the importance of prenatal screening for abnormal fetal brain development. The high prevalence 
of relative microcephaly and associated poor outcomes at birth suggests that women of Cantonese origin merit closer clinical management and follow-up to maximise fetal head development during pregnancy.

Acknowledgements The authors thank Yehua Liu (Guangzhou Medical University, China) for participating in data collection, and Michael S Kramer (McGill University, Canada) for comment on an earlier version of the manuscript. The authors state that they had no interests that might be perceived as posing conflict or bias.

Contributors This study was carried out in collaboration of the Public Health Agency of Canada with the Third Affiliated Hospital of Guangzhou Medical University in China, where the lead author holds an adjunct professorship.

Funding The authors have not declared a specific grant for this research from any funding agency in the public, commercial or not-for-profit sectors.

\section{Competing interests None declared.}

Patient consent for publication Not required.

Provenance and peer review Not commissioned; externally peer reviewed.

Data sharing statement No data are available. All data relevant to the study are included in the article or uploaded as supplementary information.

Open access This is an open access article distributed in accordance with the Creative Commons Attribution Non Commercial (CC BY-NC 4.0) license, which permits others to distribute, remix, adapt, build upon this work non-commercially, and license their derivative works on different terms, provided the original work is properly cited, appropriate credit is given, any changes made indicated, and the use is non-commercial. See: http://creativecommons.org/licenses/by-nc/4.0/.

\section{REFERENCES}

1. Leviton A, Holmes LB, Allred EN, et al. Methodologic issues in epidemiologic studies of congenital microcephaly. Early Hum Dev 2002;69:91-105.

2. Woods CG, Parker A. Investigating microcephaly. Arch Dis Child 2013;98:707-13

3. Dobyns WB. Primary microcephaly: new approaches for an old disorder. Am J Med Genet 2002;112:315-7.

4. Nawathe A, Doherty J, Pandya P. Fetal microcephaly. BMJ 2018;361.

5. von der Hagen M, Pivarcsi M, Liebe J, et al. Diagnostic approach to microcephaly in childhood: a two-center study and review of the literature. Dev Med Child Neurol 2014;56:732-41.

6. Woods CG, Bond J, Enard W. Autosomal recessive primary microcephaly (MCPH): a review of clinical, molecular, and evolutionary findings. Am J Hum Genet 2005;76:717-28.

7. Villar J, Cheikh Ismail L, Victora CG, et al. International standards for newborn weight, length, and head circumference by gestational age and sex: the newborn cross-sectional study of the INTERGROWTH21st project. Lancet 2014;384:857-68.

8. Papageorghiou AT, Ohuma EO, Altman DG, et al. International standards for fetal growth based on serial ultrasound measurements: the fetal growth longitudinal study of the INTERGROWTH-21st project. Lancet 2014;384:869-79.

9. WHO Multicentre Growth Reference Study Group. Who child growth standards: growth velocity based on weight, length and head circumference: methods and development. Geneva: World Health Organization, 2009: 242. ISBN: 9789241547635.

10. Morris JK, Rankin J, Garne E, et al. Prevalence of microcephaly in Europe: population based study. BMJ 2016;354

11. Cragan JD, Isenburg JL, Parker SE, et al. Population-based microcephaly surveillance in the United States, 2009 to 2013: an analysis of potential sources of variation. Birth Defects Res A Clin Mol Teratol 2016;106:972-82

12. Graham KA, Fox DJ, Talati A, et al. Prevalence and clinical attributes of congenital microcephaly - New York, 2013-2015. MMWR Morb Mortal Wkly Rep 2017;66:125-9.

13. Auger N, Quach C, Healy-Profitós J, et al. Congenital microcephaly in Quebec: baseline prevalence, risk factors and outcomes in a large cohort of neonates. Arch Dis Child Fetal Neonatal Ed 2018;103:F16 7-F172.

14. Bhide P, Kar A. Birth prevalence of microcephaly in India. Bull World Health Organ 2016;23.

15. Devakumar D, Bamford A, Ferreira MU, et al. Infectious causes of microcephaly: epidemiology, pathogenesis, diagnosis, and management. Lancet Infect Dis 2018;18.
16. McNeese ML, Selwyn BJ, Duong $\mathrm{H}$, et al. The association between maternal parity and birth defects. Birth Defects Res A Clin Mol Teratol 2015;103:144-56.

17. McElrath TF, Allred EN, Kuban K, et al. Factors associated with small head circumference at birth among infants born before the 28th week. Am J Obstet Gynecol 2010;203:138.e1-138.e8.

18. Krauss MJ, Morrissey AE, Winn HN, et al. Microcephaly: an epidemiologic analysis. Am J Obstet Gynecol 2003;188:1484-90.

19. Abdel-Salam G, Czeizel AE. A case-control etiologic study of microcephaly. Epidemiology 2000;11:571-5.

20. Kleber de Oliveira W, Araǔjo de Franca GV, Hage Camo E, et al. Infection-related microcephaly after the 2015 and 2016 Zika virus outbreaks in Brazil: a surveillance-based analysis, 2018. Available: www.thelancet.com

21. Baud D, Gubler DJ, Schaub B, et al. An update on Zika virus infection. Lancet 2017;390:2099-109.

22. World Health Organization. Zika causality statement, 2016. Available: http://www.who.int/emergencies/zika-virus/causality/en/

23. Liu S, Gong J, Pan Y, et al. Newborn birth weight, length, and head circumference for gestational age in Guangzhou based on the INTERGROWTH-2 $1^{\text {st }}$ standard: a multiyear hospital liveborn cohort study. The Lancet 2015;386.

24. Public Health Agency of Canada. Canadian perinatal health report, 2008 edition. Ottawa, 2008. Available: http://www.phac-aspc.gc.ca/ publicat/2008/cphr-rspc/pdf/cphr-rspc08-eng.pdf [Accessed 21 Jan 2019].

25. Gong J, Chen D, Liu S. Development of maternal-neonatal health database in Guangzhou. Chin J Obstet \& Gynecol 2015;31:1069-73.

26. Auger N, Luu TM, Healy-Profitós J, et al. Correlation of neonatal abstinence syndrome with risk of birth defects and infant morbidity. J Stud Alcohol Drugs 2018;79:553-60.

27. Liu S, Evans J, MacFarlane AJ, et al. Association of maternal risk factors with the recent rise of neural tube defects in Canada. Paediatr Perinat Epidemiol 2019;33:145-53.

28. Freund RJ, Littell RC, Spector PC. SAS system for linear mode/s. Cary NC: SAS Institute Inc, 1986

29. The Coordinating Study Group of Nine Cities on the Physical Growth and Development of Children. A national survey on physical growth and development of children under seven years of age in nine cities of China in 2015. Chin J Pediatr 2018;56:192-9.

30. Heppe DHM, Steegers EAP, Timmermans S, et al. Maternal fish consumption, fetal growth and the risks of neonatal complications: the Generation R Study. Br J Nutr 2011;105:938-49.

31. Dolk H. The predictive value of microcephaly during the first year of life for mental retardation at seven years. Dev Med Child Neurol 1991;33:974-83.

32. Leviton A, Kuban K, Allred EN, et al. Antenatal antecedents of a small head circumference at age 24-months post-term equivalent in a sample of infants born before the $28^{\text {th }}$ post-menstrual week. Early Hum Dev 2010;86:515-21.

33. Leibovitz Z, Daniel-Spiegel E, Malinger G, et al. Prediction of microcephaly at birth using three reference ranges for fetal head circumference: can we improve prenatal diagnosis? Ultrasound Obstet Gynecol 2016;47:586-92.

34. Basatemur E, Shevlin M, Sutcliffe A. Growth of children conceived by IVF and ICSI up to 12 years of age. Reprod Biomed Online 2010;20:144-9.

35. Brandes JM, Scher A, Itzkovits J, et al. Growth and development of children conceived by in vitro fertilization. Pediatrics 1992:90:424-9.

36. Miles HL, Hofman PL, Peek J, et al. In vitro fertilization improves childhood growth and metabolism. J Clin Endocrinol Metab 2007:92:3441-5.

37. Visconti K, Hennessy K, Towers C, et al. Chronic opiate use in pregnancy and newborn head circumference. Am J Perinatol 2015;32:27-32

38. Bateman DA, Chiriboga CA. Dose-response effect of cocaine on newborn head circumference. Pediatrics 2000;106:e33.

39. Chaudhry SA, Gad N, Koren G. Toxoplasmosis and pregnancy. Can Fam Physician 2014;60:334-6.

40. DuanC, NingZ, HawW, et al. Toxoplasma gondii infection among pregnant women in Guangdong Province, subtropical southern China. J Med Microbiol Diagn 2012;01.

41. Wu D, Wu J, Zhang Q, et al. Chikungunya outbreak in Guangdong Province, China, 2010. Emerg Infect Dis 2012;18:493-5.

42. Xiao J-P, He J-F, Deng A-P, et al. Characterizing a large outbreak of dengue fever in Guangdong Province, China. Infect Dis Poverty 2016;5. 